in the literature very few cases of failure of legumes which can be definitely ascribed to a predominant nodulation by ineffective strains of indigenous Rhizobia.

These observations form part of a series of investigations being undertaken on the ecological relationships of Rh. trifolii and its importance as a factor in the establishment of subterranean clover in soils of low fertility, the results of which will be reported in greater detail elsewhere.

Soil Microbiology Section, Division of Soils,

J. R. HARRIS

Commonwealth Scientific and

Industrial Research Organization,

Waite Agricultural Research Institute, Adelaide, South Australia.

1 Casas-Campillo, C., Ciencia, 9, 193 (1949).

${ }^{2}$ Abdel-Ghaffar, A. S., and Allen, O. N., Trans. Tourth Int. Cong. Soil Sci., 3, 93 (1950).

${ }^{3}$ Krasilnikov, N. A., and Korenyako, A. I., Mikrobiologiin, 13 (1) 39, (1949).

\title{
Structure of Poly-D-glutamic Acid isolated from Capsulated Strains of B. anthracis
}

WE have already shown ${ }^{1,2}$ that the poly-D-glutamic acid of molecular weight $6,400-9,000$ which $B$. subtilis secretes into the culture medium contains $\gamma$-glutamyl links (I, $R=\mathrm{COOH}$ ) in such predominance that few $\alpha$-glutamyl links (III, $R=\mathrm{COOH}$ ) can be present in the substance. This statement is based on the observation that in the acid hydrolysate of the polyamine derivative (I, $R=\mathrm{NH}_{2}$ ) prepared from the polypeptide, by Curtius degradation of the polyhydrazide (I, $R=\mathrm{CON}_{2} \mathrm{H}_{3}$ ) or by Hofmann degradation of the polyamide (I, $R=\mathrm{CONH}_{2}$ ), only $\beta$-formylpropionic acid (II) appears in quantities easily assayable by preparative methods, and no $\alpha . \gamma$-diaminobutyric acid was found to be present. Control experiments with synthetic $\alpha$-polyglutamic acid, on the other hand, readily gave $\alpha . \gamma$-diaminobutyric acid (IV) on acid hydrolysis of the degradation product.

Hanby and Rydon ${ }^{3}$ came to the reverse conclusion regarding the predominating type of the glutamyl linkages with poly-D-glutamic acid separated from capsulated strains of $B$. anthracis. Since Ivánovics and Bruckner found no difference by chemical and serological reactions between the polyglutamic acids of identical molecular weight $(6,400-7,100)$ isolated from the two species of bacilli, extension of the above degradation to poly-D-glutamic acid of $B$. anthracis appeared desirable.

For the preparation of the polypeptide, a nonsporing capsulated $B$. anthracis strain (No. A $71 T$ ) of low virulence was used, which appears to be identical as regards its morphological and cultivation characteristics with the cultures furnished by White ${ }^{5}$ for Hanby and Rydon's experiments. This strain was raised from a capsulated strain (No. A 71) of high virulence which was inoculated into horse serum, then kept for three weeks at $37^{\circ}$ and used afterwards for isolation of the strain in question. Isolation of the crude polypeptide from agar cultures of<smiles>[R]C(NCCCC(=O)O)C(C)C(=O)O</smiles>

(I)

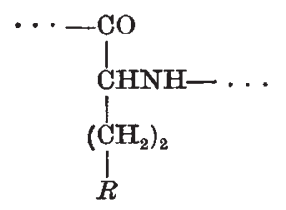

(III) this strain followed strictly Hanby and Rydon's method $^{3}$. This substance was dried in vacuo at room temperature, then esterified with methyl alcohol by addition of acetyl chloride. The crude ester was now repeatedly fractionated from methanol by precipitation with increasing quantities of ether. After stepwise extraction with cold water there remained an undissolved fraction which contained no ash and had the average molecular weight of $45,000-53,000$ (van Slyke), which is in the order shown by specimens described by Hanby and Rydon. Analysis demonstrated about 75 per cent esterification of the carboxyl groups. The slight solubility in water appears to be due to the presence of the remaining free carboxyl groups. In degradation, both of the polyhydrazide and polyamide prepared from the polyester, only $\beta$-formylpropionic acid (II) could be detected by preparative methods but no $\alpha . \gamma$-diaminobutyric acid (IV). This suggests that also in the high molecularweight poly-D-glutamic acid of $B$. anthracis it is the $\gamma$-glutamyl link which is the predominant type.

Details of this work will be published elsewhere. V. BRUCKNER

Institute of Organic Chemistry, University of Budapest.

Institute of Medical Chemistry,

\section{G. DEnes}

University of Budapest. April 6.

${ }^{1}$ Kovács, J., and Bruckner, V., Research, 5, 194 (1952) ; J. Chem. Soc., 4255 (1952). Bruckner, V., Kovács, J., and Nagy, H., J. Chem. Soc., 148 (1953)

${ }^{2}$ Kovács, J., Bruckner, V., and Kovács, K., J. Chem. Soc., 145 (1953). Bruckner, V., Kovács, J., and Kovács, K., J. Chem. Soc. (in the press).

${ }^{3}$ Hanby, W. E., and Rydon, H. N., Biochem. J., 40, 297 (1946).

- Ivánovics, G., and Bruckner, v., Naturwiss., 25, 250 (1937); Z. Immunforsch., 90, 30 ; 81, 175 (1937).

White, B., Biochem. J., 40, 308 (1946).

\section{Intracellular Distribution of Rhodanese in Cardiac Muscle}

THE distribution of enzymes within animal tissues has been studied most extensively in the case of liver. Particular. interest has centred round the large granules (mitochondria), which have been found to contain the components of the cytochrome system, to catalyse the oxidation of all the citric acid cycle intermediates and the oxidation of fatty acids, and to carry out oxidative phosphorylation ${ }^{1}$. Recent work on cardiac muscle has shown that the particulate fraction (sarcosomes ${ }^{2}$ ) has a similar complement of respiratory enzymes and co-enzymes ${ }^{2.3}$; and there has been a tendency for sarcosomes to be considered identical with mitochondria. However, a large number of other enzymes are known to be associated with liver mitochondria, and it was of interest to investigate the distribution of one of these nonrespiratory enzymes in cardiac muscle.

The enzyme chosen for study was rhodanese, which catalyses the reaction,

$$
\mathrm{HCN}+\mathrm{Na}_{2} \mathrm{~S}_{2} \mathrm{O}_{3} \rightarrow \mathrm{HCNS}+\mathrm{Na}_{2} \mathrm{SO}_{3} .
$$

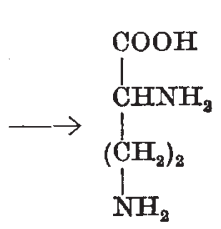

(IV)
Most of the rhodanese activity of liver has been found in the mitochondria 4 .

Calf cardiac muscle was homogenized in $0.88 M$ sucrose $^{5}$ and three fractions were obtained by differential centrifugation : (a) myofibrillar- 